By

Teng Moua

A Research Paper

Submitted in Partial Fulfillment of the

Requirements for the

Master of Science Degree

With a Major in

Marriage and Family Therapy

Approved: 2 Semester Credits

\title{
Thesis Advisor
}

The Graduate College

University of Wisconsin-Stout

May 2003 
The Graduate College

University of Wisconsin-Stout

Menomonie, Wisconsin 54751

\begin{tabular}{llc} 
& ABSTRACT \\
Moua & Teng & (NONE) \\
\hline (Writer) (Last Name) & (First) & (Initial)
\end{tabular}

The Hmong Culture: Kinship, Marriage \& Family Systems (Title)

\begin{tabular}{|c|c|c|}
\hline Marriage \& Family Therapy & Dr. Charles Barnard & May, 2003 \\
\hline (Graduate Major) & (Research Advisor) & (Month/Year)(No. of Pages) \\
\hline
\end{tabular}

(Name of Style Manual Used In This Study)

The purpose of this study is to describe the traditional Hmong kinship, marriage and family systems in the format of narrative from the writer's experiences, a thorough review of the existing literature written about the Hmong culture in these three (3) categories, and two structural interviews of two Hmong families in the United States. This study only gives a general overview of the traditional Hmong kinship, marriage and family systems as they exist for the Hmong people in the United States currently. Therefore, it will not cover all the details and variations regarding the traditional Hmong kinship, marriage and family which still guide Hmong people around the world. Also, it will not cover the 
whole life course transitions such as childhood, adolescence, adulthood, late adulthood or the aging process or life core issues.

This study is divided into two major parts: a review of literature and two interviews of the two selected Hmong families (one traditional \& one contemporary) in the Minneapolis-St. Paul metropolitan area. The two interviews of these two families from two different generations are to gain new perspectives of both what has changed, and what has remained the same in their beliefs and practices of the traditional Hmong kinship, marriage and family systems after living in the United States for more than eighteen (18) years. As the Hmong-American families, in general, continue to acculturate more and more into the American mainstream society and culture, the information collected from the two interviews will be used to suggest the trends of change in the beliefs and practices of the traditional Hmong kinship, marriage and family structures in the near future. 


\section{ACKNOWLEDGMENTS}

I want to take this opportunity to thank my wife Diane Vang and our two beautiful daughters, Victoria and Jasmine, for their love, support, patience and understanding during my study, and especially when I worked on my research project. I wish to thank my two thesis advisors, Dr. John Williams and Dr. Charles Barnard, for assisting me in making this research project possible. I would also like to thank the four MFT professors, Dr. Charles Barnard, Dr. Bruce Kuehl, Dr. John Williams and Brier Miller-Minor for all your encouragement and assistance during my two-year study at UW-Stout. I cannot express enough gratitude to Bruce Minor at Ruben Lindh Learning Center in Minneapolis for believing me and giving me his advice, support and encouragement on a continuous basis regardless whether I work for him or not. Finally, I want to thank my supervisor Michael Brogdon and two co-workers, Vicki Moore and Kristen Rasmussen, for all your assistance and understanding of my academic endeavor. Everyone of you has assisted me in some ways, and has made a positive impact in my life. I could not have accomplished my goal of obtaining a master's degree without the assistance from everyone of you. I cannot thank you enough for all your support. 


\section{TABLE OF CONTENTS}

Page

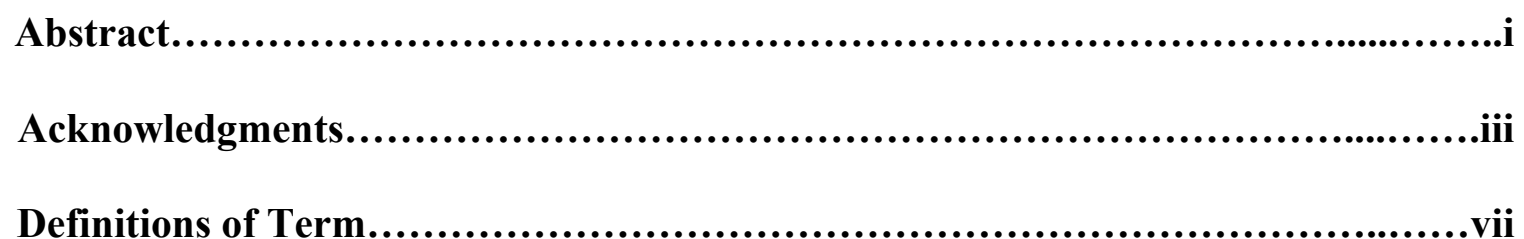

Chapter I Introduction Of The Hmong History.......................................1

Statement of The Problem.....................................................2

Chapter II Review of Literature.....................................................4

The Hmong Kinship System \& Its Functions...............................4

A Basic Social Structure of the Hmong 18 Clans...................................6

A Social Legitimacy for Marriage via The Rule of Exogamy..............6

The Hmong Society \& Its 18 Kinship Clans................................7

The Hmong Patrilineal Descent System With 6 Oral Generations.......7

An Example of The Descent System in Practice.....................10

The Hmong Concept of Honor \& Shame As A Discipline Of

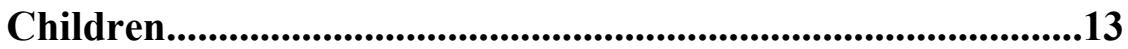

Traditional Hmong Marriage System.........................................13

Two Functions of Hmong Marriage..................................13

The Marriage Path of Formal Request...........................15

Courtship..........................................................15 
Bride Price \& Dowry .................................................16

Formal Marriage Negotiation.....................................17

2 Alternative Traditional Marriage Paths...........................18

Voluntary Elopement............................................19

Traditional Marriage Protocol................................20

Bride Abduction or Kidnapping..............................20

Patri-Local Residence...........................................22

The Last-Born Son \& His Traditional Duties...................23

The Bride As A New Family Member...........................23

The Wife Induction To The Husband's Extended Family......24

The Traditional Hmong Family System...............................25

The Nuclear Family In The Dominant Extended Family.......25

The Hmong Family Division of Labor...........................26

Farming..............................................26

Household..................................................26

The Hmong Form Of Polygamy..............................27

Levirate..............................................27

The Value of Male Children Over The Female Children......28

Chapter III Methodology ..........................................................................29

Introduction...................................................29

Specific Research Questions....................................29

Subjects (The Two Hmong Families)...........................31

Selection Process..........................................31 
Material......................................................32

Procedure........................................................33

Chapter IV Data Findings \& Summary ......................................................34

Introduction...................................................34

Kinship System.............................................35

Marriage System...........................................38

Family System.................................................42

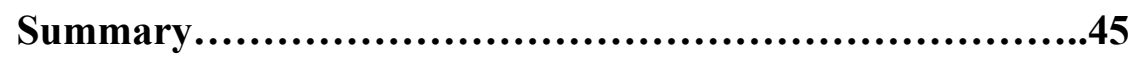

Prediction Of The Trends of Change \& Conclusion...............45

Conclusion.....................................................................46

References............................................................................48

Appendices........................................................................49 


\section{Definitions of Terms}

1. Affinal $($ adj. $)=$ marital

2. Agrarian $($ adj. $)=$ agricultural

3. Bride price (noun)=the amount of money or property of value which the groom's family paid to the bride's family.

4. Clan (noun) $=$ a biological and social group of people which composed of several families, claiming descent from a common ancestor, bearing the same family surname, and following the same chieftain or leader.

5. Consanguine $($ adj. $)=$ blood

6. Dowry (noun) $=$ a financial gift or present of value which the bride's parents or family gave to the newly wedded couple to help start their new married life.

7. Exogamy (noun)=marriage outside of one person's clan.

8. Go-betweens (noun)=intermediaries; people who deal with each of the two sides in making arrangements between them.

9. Hmong (noun)=an ethnic minority group of Asian people who immigrated to the United States after 1975 from Laos.

10. Levirate (noun) $=$ a compulsory marriage of a widow by her deceased husband's younger brother.

11. Patrilineal descent (noun) $=$ a derivation or designating of descent or kinship through the father's side instead of the mother's.

12. Polygamy (noun) = a practice of having two or more wives or husbands at the same time; a plural marriage. 


\section{Chapter I}

\section{Introduction of the Hmong History}

According to the ancient Chinese history, the Hmong as a culturally unique group of Asian people lived in central Siberia. Central Siberia was their original homeland. In 2500 B.C., the Chinese and other Asian groups conquered the Hmong homeland and its people, and forced them to flee south into northern China. In northern China, they settled and started a new civilization on the banks of the Yellow River. Their civilization was prosperous and successful until the Chinese attacked them again for their fertile land along the Yellow River. Due to the intense competition for land, the Chinese continued to attack the Hmong and their peaceful agrarian civilization. Again, the Hmong had no choice, but to fight or flee. They defended their civilization, culture and way of living by fighting a series of warfare against the Chinese invaders. The Hmong were defeated and eventually forced to flee again. This time they settled in the southern parts of China which are known as Hepeh and Hunan provinces today. There are approximately 8 to 12 million Hmong still living in this region of China. The other 1-2 million Hmong are found living in Laos, Thailand and Northern Vietnam as a result of migration during the mid-1800's (Quincy, 1988).

The Hmong in Laos were recruited and trained by the U.S. Central Intelligence Agency (CIA) in the early 1960's as a secret army (guerrilla force) to assist the U.S. war efforts during the Vietnam War. During the Vietnam War, the Hmong fought directly against the North Vietnamese forces and a smaller political faction of Lao Communists known as the Pathet Lao. When the United States withdrew its armed forces from the Vietnam War in 1975, the Hmong immediately became unprotected targets of the Lao 
Communist Government which came to power in Laos that same year. They lost their country and needed to flee their homeland which they had settled once more. Again, the Hmong had no other choice, but to continue their peaceful way of life. As a result, hundreds of thousands of Hmong escaped the genocide of the Lao Communist Government. This time they settled in France, Canada, Australia, New Zealand, West Germany, the United States, and even Argentina as political refugees in order to continue their peaceful way of life. Statistically, the majority of the Hmong refugees (about 200,000) settled and restarted their new lives in the U.S. (Teng Moua's personal record, 1999).

\section{Statement Of The Problem}

The purpose of this research paper is to describe the Hmong traditional kinship, marriage and family structures from the author's experiences, and a thorough a review of the existing literature written about the Hmong culture in these three (3) categories. This research paper only gives a general overview of the Hmong traditional kinship, marriage and family systems which are still practiced by the Hmong in the United States. Therefore, it will not fully cover all the details and variations regarding the Hmong traditional kinship, marriage and family systems which are still practiced by all the Hmong around the world. The writer will not cover the entire Hmong life course transitions or issues such as childhood, adolescence, adulthood, late adulthood, aging process, and life issues.

This study is divided into two major parts: a review of literature and two structural interviews of the two selected Hmong families (one traditional \& one contemporary) in the Minneapolis/St. Paul metropolitan area. The interviews of these 
two Hmong families from different generations were designed to gain new perspectives of both as to what has changed, and what has remained the same in their beliefs and practices of the traditional Hmong kinship, marriage and family systems after living in the United States for more than 18 years. As the Hmong-American families, in general, continue to acculturate more and more into the American mainstream society and culture, the information gained from the two interviews will be used to suggest the trends of change in the beliefs and practices of the traditional Hmong kinship, marriage and family systems in the near future. 


\section{Chapter II}

\section{Review of Literature}

\section{The Hmong Kinship System \& Its Functions}

The Hmong kinship is the most important biological and social structure among all those systems in the Hmong society. It is a blood and marital relationship that defines and connects those consanguine (blood) relatives in the same clan (kwv tiv), affinal (marital) kin within other clans (neej tsa), and between them. The Hmong society recognizes both the consanguine and affinal relationships between blood and marital relatives. However, the Hmong who are always born and belonged to the 18 major clans for life, have established and valued their consanguine ties as the primary, most important relationships among their blood (paternal) relatives. On the other hand, they also recognize their marital ties as the secondary relationships between them and their affinal kin who belong to different clans. The marital ties are very important to not only connect those consanguine and affinal relatives through marriage but also strengthen their clans through mutual understanding, reciprocal responsibilities and economic cooperation.

The Hmong kinship system consists of a set of specific kinship terms, definitions, assignments of rights and duties, and codes of appropriate behavior to specific kinship positions or roles. It also contains a set of rules that define how the Hmong are related to each other through the consanguine (blood) and affinal (marital) relationships in their society. In addition to the formal kinship system based on the genealogical connection and marriage, the Hmong recognize "ritual" form of kinship such as adoption. To understand and display the importance of their kinship system in their daily lives, the 
parents teach their children at an early age to learn and use appropriate kinship terms as words of relationship and respect to address their consanguine relatives in their clans and affinal kin from other different clans, including friends of their parents, elderly strangers, neighbors and acquaintances. For example, a young child could use the kinship terms, grandparents, uncles, aunts, and older/younger brothers/sisters to address both his/her consanguine and affinal grandparents, uncles, aunts, brothers and sisters as well as nonblood and non-marital friends of their families, elderly strangers, neighbors and acquaintances.

When the child addresses his/her consanguine relative and affinal kin with the appropriate kinship terms, it indicates that the child not only understands his/her kinship position, relationship, code of behavior and mutual responsibility to those specific relatives, but also to their kinship positions, relationships, codes of behavior and their mutual responsibilities to him or her. However, when a child applies these kinship terms to strangers of older ages, it simply conveys a cultural sign of respect and politeness. Why? In the Hmong society, respect from others is gained through one's age, knowledge, life experiences, wisdom and education. Therefore, it is expected that the young would show more respect and politeness toward the old and elders in their families, clans and society. Most Hmong elders agree that the Hmong kinship system is the most important basic education for all Hmong children to learn and gain a understanding of. This knowledge is the most essential part of the Hmong culture for them to gain a sense of who they are as Hmong, and their relationships to their family members and relatives (both consanguine and affinal). Kinship is the Hmong heritage of relationships, respect, solidarity and mutual obligation in the family, clan and society. 


\section{A Basic Social Structure of The Hmong 18 Clans}

The Hmong kinship system also becomes a very important institution with several essential functions to fulfill for the Hmong individuals, extended family and society. It is the basic social structure that organizes the Hmong society into the 18 major kinship groups called clans. The 18 clans as a social organization provide life-time memberships and ongoing support (both material and spiritual) to their consanguine members from birth to death. Also, it is the basic founding structure to organize each clan into several hundred social units called extended families. The extended families are smaller kinship groups within the clans which provide many of the most essential functions for their members (young and old) in the Hmong society. This topic of the traditional Hmong extended family will be discussed in more detail later.

\section{Social Legitimacy For Marriage Via The Rule of Exogamy}

Finally, the Hmong 18 clans support the institution of marriage by providing a social legitimacy through the rule of exogamy for each of the clans' members (both male and female) to court and marry others outside of their clans. The rule of exogamy is a customary procedure which (1) prohibits members of the same clans to get married with each other, and (2) only allows members of the same clans to marry those outside of their clans. For example, a male of the Lee clan absolutely cannot marry with a female of the Lee clan or vice-versa, even if they are never actually related to each other through blood or marriage or never know each other at all. According to the rule of exogamy, he is only allowed to marry those females of the non-Lee clans. Why? The Hmong rationale is that in theory all members of the same clans were biologically related in the beginning of the creation of human kind and descended from the same ancestors. In both theory and 
practice, they are related to each other as brothers and sisters simply because they have the same surnames and belong to the same clans. Therefore, they cannot have courtship and get married with each other, but rather only having courtship and marriage with those members who belong to different clans. As these above examples indicate, the Hmong kinship system fulfills many important functions, and is the major regulator of social life such as the social, political, legal and educational institutions for all Hmong, their extended families, clans and agrarian society.

\section{The Hmong Society \& Its 18 Clans or Social Groups}

As a patrilineal, patri-local tradition, the Hmong society is made of 18 major kinship groups called clans. The Hmong oral history states that each clan is believed to trace its unilineal descent from a known founding male ancestor. This is in keeping with the strong patrilineal tradition among the Asian people. In other words, the Hmong society has a patrilineal descent system which allows all the 18 clans to trace their unilineal descents from 18 common male ancestors through oral tradition. As a result, they never trace their unilineal descents through the mothers' sides. Because the Hmong written form of language was destroyed and lost a long time ago, the Hmong would trace their unilineal descents only through the oral tradition of collectively remembering of those who are their known founding male ancestors and descendants.

\section{The Hmong Patrilineal Descent System With 6 Oral Generations}

Orally speaking, the Hmong patrilineal descent system is collectively drawn and traced back for six (6) paternally consanguine generations which are then assumed to come from a known founding male ancestor (s). This means that all those Hmong individuals whose life-time memberships and affiliations belong to the same clan orally 
trace their unilineal descent through their fathers' sides of the family (patrilineal descent). The Hmong patrilineal descent system is divided into six (6) easily recognizable generations. This descent system of six generations serves two important functions. First, it is the basic structure that divides all those known ancestors and descendants into 6 different generations, depending upon their birth orders along the unilineal descent line. Secondly, it provides all those individuals (both ancestors and descendants) in each generation with a set of specific kinship positions or roles, relationships, mutual responsibilities and codes of expected behavior. In this structural organization, all those individuals who belong to the same generation (let's say the children's generation as the starting point) according to their birth orders, are considered as consanguine brothers and sisters among themselves. In other words, they are paternally related by blood as brothers and sisters.

Behaviorally, they are expected to call and treat each other like siblings would normally do as well as giving each other mutual support (both material and spiritual) throughout their lives together whenever ones are in need of the other's assistance or services. However, to the three generations directly above them, they are related and considered as children to those in the parent's generation, grandchildren to those in the generation of grandparents, and finally great grandchildren to those in the great grandparent's generation. To the two generations directly below them, they are related and considered as parents to those in the generations of grandchildren and grandparents to those in the great grandchildren's generation. As the descent system chart attached on the appendix section indicates, the children's generation is used as the starting point when 
a person traces their descent vertically upward. The parent's generation is used as the starting point when one traces their descent vertically downward.

The general "rule of thumb" is that those descendants in the generations below would consider and treat those ancestors in the generations above them as parents, grandparents and great grandparents because they are born into the descending generation (the rule of birth order). Reciprocally, those ancestors in the generations above would consider and treat those descendants in the generations below them as children, grandchildren, and great grandchildren, according to the expectations of their kinship roles/positions, relationships, codes of behavior and mutual responsibilities. Therefore, their birth orders dictate their fixed kinship positions or roles such as children (sons and daughters), grandchildren and great grandchildren. Further, their kinship roles / positions dictate their consanguine relationships, codes of behavior and mutual responsibilities for them to keep and fulfill toward those in their generation as brothers and sisters, and to those ancestors above them as children, grandchildren and great grandchildren. The birth orders of those ancestors also dictate a similar set of required kinship positions/roles, relationships, codes of behavior and mutual responsibilities for them to carry and fulfill toward those in their generation as consanguine siblings, and those in the descending generations as consanguine parents, grandparents and great grandparents.

By establishing this descent system with 6 generations, all those members who belong to the same clan are automatically born into certain generations based upon their birth orders, and know exactly their set of specific kinship roles/positions, relationships, codes of behavior and mutual responsibilities to each other as blood relatives for life. This descent system makes it easier for all the Hmong people to trace their unilineal 
descents vertically from one generation to the next one, including the identification of which ancestors and descendants belong to which generations. When they locate the generations of their ancestors and descendants, they will gain a clear understanding of the identified relatives' kinship roles, responsibilities and codes of behavior, depending upon their specific relationships to those consanguine members in their clans.

\section{An Example of The Hmong Descent System In Practice}

More importantly, this descent system helps shape people's behavior and lives to perform their required kinship roles and responsibilities, maintain their relationships and display their codes of behavior to each other as consanguine relatives for life. For example, two Hmong men meet for the first time without knowing if they are related to each other. They would ask each other for both their first and last names, and discover that one is named "Jack Lee" and the other, "Paul Lee." Their first names are to identify who they are. Their last names are to tell each other of what are their surnames and identify their clan.

By simply mentioning their surnames "Lee" to each other, they could tell that they share the same last name and belong to the same Lee clan, in theory, are blood relatives. This means that they are related to each other as blood relatives. Again, the Hmong 18 last names are the same as their 18 clans' names. In the case where two of them have two different last names such as Yang and Cha, then it means that they do not share the same surname and belong to the same clan. Therefore, they do not have any consanguine relationship to each other. However, this does not rule out a possibility that they might have an affinal (marital) relationship through one or a few of their affinal (marital) kin who may have been married to their consanguine relatives. For Jack and 
Paul, the next step for them is to find out how they are related to each other by blood, so they could call each other with the appropriate kinship terms.

No matter how distant they are from each other, they usually have at least two starting points to find out which generations in the Lee clan's descent system does each of them belong to. The first starting point is the Lee clan leader. If one or two of them knows how he is related to the clan leader and his generation, then they would have a better chance of knowing how they are related to each other and to which generations do they belong. After a brief discussion, if they could not still identify or are not sure how they are related to the clan leader, they could always consult with their fathers, uncles or elders of their clan. Let's say that Jack identifies himself as a younger brother of the clan leader because he is born into the same generation as the clan leader is. For Paul, he says that he calls the clan leader uncle. As soon as they know how they are related to the clan leader, they could tell that Jack is in the ascending generation of parent, and Paul is in the descending generation of children.

These two different generations indicate that they are related to each other as father Jack and son Paul. Due to the fact that Jack's birth order is in the parent's generation, his kinship role, relationship, responsibility, and code of behavior toward Paul is similar to Paul's biological parents'. Reciprocally, Paul's set of kinship roles, relationship, responsibility and code of behaviors toward Jack is similar to Jack's biological sons. According to the Hmong descent system, they are now related to each other as father and son regardless of their age difference. More importantly, they are required to call and treat each other as father and son. This descent system, in deed, helps 
shape their attitude and behavior toward each other in the way they relate and interact with one another like son and father.

Due to the virtue of their birth orders, they both have fixed kinship roles, responsibilities, relationships and codes of behavior toward each other. They are expected to call each other with appropriate kinship terms. Jack would call Paul "son Paul," and Paul would call Jack "father Jack" in the Hmong society. Their behaviors are expected to make an appropriate reflection of their appropriate kinship roles and relationships. This means that Paul is expected to behave well and show high regard such as respect, politeness, obedience, honesty, royalty, trustworthiness, generosity and reliability to his father Jack. In fact, the Hmong society is required that Paul regards and treats Jack like his own father. In return, Jack is required to regard and treat Paul as if he were his own son.

By relating to each other as father and son, Jack and Paul are expected to fulfill their mutual responsibilities to one another whenever one has a need for the other's support, services or cooperation. This mutual cooperation or assistance is an ongoing support system, and it lasts for life. Acting as one of Paul's parents, Jack shares an indirect role and responsibility in the area of discipline for Paul. He is given a share of parental rights to discipline Paul and look after his best interests: development, education, health, future and success, whenever Paul needs his assistance and services. Indirectly, this share of kinship role and responsibility states that Jack could discipline and support Paul whenever he deems it appropriate. For example, if Jack sees Paul misbehave or do something wrong, he could discipline him appropriately. Jack is even allowed to shame Paul for his mistakes or misbehavior as a way to discipline and change his bad behavior. 
This action on Jack's part is rightfully permissible and legitimate for him to do so. As the father with certain amounts of parental roles and responsibilities, Jack only does what is best for Paul to become a decent person in his extended family, the Lee clan and Hmong society.

\section{The Hmong Concept of Honor \& Shame As A Discipline Of Children}

The Hmong parents believe and practice the concept of shame and honor frequently as a way to discipline their children by shaping their behaviors. This concept is different from the American code which emphasizes unconditional love. In their eye, if their children have good manners or behaviors and become "good persons" in the Hmong society, they will bring honor, pride and respect to their extended families and clans. However, if their children grow up having poor manners and becoming "bad people," they will not only bring shame, disgrace and "a loss of face" to themselves, but also to their extended families, especially their parents and clans. Due to this belief and practice of honor and shame, the Hmong society even dictates that great grandparents (if still alive), grandparents and parents share certain amounts of parental responsibilities to discipline and shape children's behaviors or manner, so they could grow up to become "good people." Sometimes the Hmong community at large even allows to discipline and shame other parents' children when they misbehave or do something in-appropriately (Teng Moua' personal experience).

\section{Traditional Hmong Marriage System}

\section{The Two Functions of Hmong Marriage}

The traditional Hmong marriage serves two important functions. The first function is to unite a man and woman into a social unit for the purposes of procreation and economic production. The second function is to create reciprocal economic, political 
and ceremonial ties between their respective kinsmen from the 18 clans. Although the Hmong parents recognize the importance of having strong ties with many other clans, they usually respect the individual choices and affections of their young children when it comes to arrange a marriage. Therefore, they do not force their young children to marry someone whom their children steadfastly refuse. Only a small number of Hmong parents who possess a large amount of wealth and power would try to hold exclusive parental rights to arrange marriages for their sons or daughters. However, even in this rare occasion of arranging marriages between those few wealthy Hmong families, the parents still allow their sons or daughters to have the final say. Hmong parents strongly want their sons' and daughters' marriages to be happy and successful. Also, divorce is culturally inappropriate. Divorce is culturally taboo and inappropriate. By giving the freedom of choice to their children, they hope that the marriages of their children would be more successful, and divorce could be avoided or prevented from happening in the future. These are some of the important reasons why Hmong parents allow their children a freedom of choice to choose their own marriage partners. Nevertheless, there are important things for Hmong parents to consider with their sons or daughters when they are thinking about getting married with certain prospective marriage partners. These important things that the Hmong parents generally look at are the relative wealth, prestige, family size and reputation, and residence or family life style of their sons' or daughters' prospective marriage partners and their families. Many times these important things may constrain their sons' or daughters' freedom of choice in selecting their marriage partners. 


\section{The Marriage Path of Formal Request (Begging) By The Groom's Family}

In the Hmong agricultural society where the extended families' economic survival depended heavily upon the ability of their family members to produce enough food supplies to feed its members, the traditional Hmong marriage has occurred at an early age. The prospective marriage partners have been generally young. The girls were between the ages 14 and 20. The boys were between the ages of 17 to 25 . Traditionally, the formal marriage procedure is initiated by the groom's father, his older married brothers or clan leaders. This marriage path is called the formal marriage request or begging by the groom's family. If the groom has no father or older married brothers, he could ask other male relatives and his clan leaders to assist him in making the formal marriage request to the prospective bride's parents. In most cases, the bride has already given him her consent to go and make the formal marriage request during their courtship.

\section{Courtship}

The courtship is a brief period of social contact between them. During the courtship, premarital sexual involvement is strictly prohibited because a "naughty" daughter's promiscuous sexual behavior would bring the biggest shame and "loss of face" to herself, the good name and reputation of her parents, extended family and clan. If they have any sexual relationship, it mostly means that they have agreed or will get married as soon as possible to prevent the shame, embarrassment and loss of face from happening to the girl, her extended family and clan. In the case where the boy has not made up a decision on any prospective wives, his father, older brothers, male relatives and clan leaders could assist him by looking for the "suitable" girls and helping him make the final choice on one particular girl. When they do this for him, they act as his 
representative who would go to the girl's family and initiate the formal marriage request on his behalf (Scott, 1986).

\section{Bride Price \& Dowry}

Once the girl's family refuses the boy's family's formal marriage request, there is no marriage or wedding. However, when the girl's family accepts the boy's marriage request, the formal negotiations would begin between the two families through the groom's two go-betweens and the bride's two go-betweens regarding the bride-price, dowry and the costs of the wedding or marriage ceremony. The bride-price for the Hmong community in the United States is temporarily set between $\$ 4,500.00$ to $\$ 6,000.00$ today. In Laos, the bride price is set between 4 to 6 silver bars. It will serve as the marriage contract or security between the bride's family and clan, and the groom's family and clan.

The bride price is refundable if the marriage gets disrupted and dissolved less than 5 years; and the bride is found to be responsible for the cause of their marriage breakup. The time limit for the groom and his family to ask for the refund of their bride price is around 5 years. After the 5-year time limit, there is no guarantee that they would receive their bride price back from the bride's family, regardless of who (the groom or bride) may have caused the breakup of their marriage. The rationale between this 5-year time limit is that the bride has made more than enough contributions in terms of childbearing, food production, and material resources to him and his extended family after 5 or more years of marriage. Therefore, traditional Hmong marriage custom indicates that there is no point of even asking for the refund of the bride price after 5 or more years of marriage. The bride's family's dowry is conversely considered as a smaller financial gift in a much 
less amount than the groom's family's bride price. The purpose of the dowry is to assist the newly wedded couple in starting their new married life together in the groom's extended parental house.

\section{Formal Marriage Negotiation}

The formal marriage negotiation regarding the bride-price, dowry and the high costs of the marriage ceremony generally takes place on the $4^{\text {th }}$ or $5^{\text {th }}$ day in the bride's parental house after the bride has been in the groom's parental home for 3 days and gone through the "welcome ritual." The welcome ritual is a first joyful celebration for welcoming the bride as a new member into the groom's family and clan. As soon as the marriage negotiation is agreed upon and completed, the groom and his parents are asked and required to immediately pay the bride-price and costs of marriage ceremony in full to the bride's family. Once the bride-price is paid and received by the bride's family, it is up to the bride's parents to reach a decision on how much money they would like to give back to the groom and his extended family as a dowry. Again, the dowry is usually small in amount (about $10 \%$ of the total bride price). The dowry is given back to the bride and groom to start their new married life together. Traditionally, it is expected that the groom and his family pay up to $90 \%$ of the wedding costs on the next following day. On the next day, the groom and his consanguine male relatives who are his assistants will prepare a large meal to celebrate the marriage ceremony with a large number of guests (about 100 or more people). When the marriage ceremony is officially over, the groom and his group of delegates will prepare to immediately leave the bride's parental home and return to the groom's parental home at last. This officially concludes the marriage negotiation and ceremony ( Teng Moua's personal knowledge and experiences). 


\section{Two Alternative Marriage Paths}

The above marriage procedure is the most preferred and normative path to marriage for the traditional Hmong. However, the Hmong society also develops two alternative marriage procedures to accommodate other different situations which may lead or force a man and woman to get married. For example, one of the situations which may lead a couple to get married immediately is when the woman gets pregnant during their intense courtship, and her family discovers the pregnancy. In this case, the bride's family generally takes the initiative (but not always) to approach the groom's family with the fact and demand a marriage negotiation immediately. Upon receiving the fact from the bride's family, the groom's family would mostly acquiesce to the request of the bride's family, even if her family demands a higher bride-price and extra money to compensate the grievance caused by the groom. If the groom's family does not acquiesce immediately, it would risk its chance of losing the bride and a potential heir to its lineal and clan. What is even more risky is that the groom's family may have to pay a high compensation in the form of money which is equivalent to the bride-price without gaining the bride and her baby. This marriage dispute could also produce a bitterness for both families and a harmful effect to the present and future relationships of the two clans. As a result, the groom's family, especially his parents, older married brothers, and male relatives would do everything in their own power to convince him to accept the marriage, even if he refuses. From the view of his family and clan, his acceptance of the marriage would make things easier for them in many ways (financially, emotionally and socially). His acceptance could also dissolve the marriage dispute and prevent the relationships 
between the two families and clans from further deteriorating. Due to the high level of respect and dependence he has for his male elders, he would mostly listen to them and go along with their final decision.

\section{Voluntary Elopement}

Another alternative form is a voluntary elopement. If a courting couple decides to get married, but the girl's parents would not accept her current boyfriend to be her future husband or that her parents try to force her to accept another young man or older man against her will, she has the option to voluntarily flee with her lover to his parents' home as a traditional way of getting married to the man of her choice.

In the Hmong society, the parents' refusal or disagreement to allow their daughters to marry the men of their choice does happen occasionally. If a girl is strong against her parents' choice of men, she still has two options to straighten this disagreement out (1) by discussing this matter with her own extended family and clan to reach an acceptable decision, or (2) voluntarily fleeing with her lover to be married with him. In the case where a girl or woman is being asked to marry a man whom she does not love or care for, she would try to convince her parents or extended family members to understand her concerns and viewpoints. A threat of suicide or self-harm could also be used in the negotiations with her parents. Due to fact that Hmong parents highly value and understand the importance of successful marriage and personal freedom of choice, they generally do not force their daughters to marry those men whom they do not wish to marry. In the minds of Hmong parents, forced marriages would mostly result in unhappy married lives and divorces later down the road. 


\section{Traditional Marriage Protocol}

No matter which marriage path the couple decides to take, the groom's parents must secure and dispatch two messengers to the bride's parents or family to officially announce that she left voluntarily with the groom to marry him. The groom also wanted to marry the bride. Upon hearing the announcement from the two messengers, the bride's parents would formally accept her marriage to the groom. The next step is to keep the newly wedded couple in the home of the groom's parents or male relatives for 3 days. On the $3^{\text {rd }}$ day, the groom's family would do a "welcome ceremony" as a traditional way to physically and spiritually welcome her to the groom's extended family and clan. On the $4^{\text {th }}$ day, his consanguine male relatives and two go-betweens (Mej Koob) who are his representatives would approach her parents to begin the formal marriage negotiation about the bride-price, dowry and wedding ceremony which traditionally proceed as in a normal marriage. The majority of voluntary elopements successfully result in marriage. Some elopements, however, do not lead to marriage because the girls are too young or the girls' parents find the boys or men and their families very unsuitable and objectionable for their daughters to be married with.

\section{Bride Abduction or Kidnapping}

Lastly, the Hmong society has and recognizes that bride abduction or kidnapping as another alternative way toward marriage. The bride abduction involves the kidnapping of a girl by the prospective husband without her personal consent and her family's approval. The prospective husband always receives assistance from a small group of his close male relatives or male friends during the bride abduction. The bride kidnapping preferably takes place while the girl is away from her home and alone by herself. This 
would make it easier for the prospective husband and his kinsmen to physically kidnap and take her to the home of the hopeful husband (Scott, 1986). As soon as the bride is brought to the home of the hopeful husband's family, his parents are obligated to secure and send two messengers to inform her parents of the girl's abduction and the hopeful husband's intention to marry her. When the girl's parents receive the news, they have two options to pursue. The first option is for her parents to go to the abductor's family house and demand the release of their daughter immediately, if they do not find him and his family suitable. Her parents' physical presence and strong demand or objection at the abductor's family home could lead to the immediate release and safe return of their daughter back to her family. The second option which her parents have is simply to accept the abduction of their daughter as an alternative way for their daughter and her prospective husband to get married, if they find or have a strong belief that the abductor is a good person and husband, and his family is suitable for her (Teng Moua, 1999). As George Scott (1986) writes, "Once the abduction had occurred, the [normal marriage] procedure would follow as with elopement, with these differences: the abducted girl's family would search for her with much greater intensity, and if they [her parents] found her before the three days had expired, the least the abductors could expect was much acrimony and a higher amount of compensation, and the most, violence. Also, if they [the abductor and his kinsmen] had taken her against her will, they would have the added burden of guarding against her escape, while, at the same time, her would-be husband tried to console her with promises of kindness and future visits with her family if she agreed to be his wife. Of course, even if she consented and the negotiations with her family went peacefully, he knew he could never be assured of her loyalty, let alone her affection. He also knew that he would have to continue to treat her with greater kindness than had he married her in the normal way, because the slightest mistreatment was likely to be accepted by her family, as well as by the community at large, as grounds for her return, and usually without a refund of the bride-price. All in all, then, a genuine abduction was not a very promising way to obtain a wife, which undoubtedly accounted for its rarity. In fact, it was almost always an act of final desperation on the part of a man who either himself or whose family was severely flawed - e.g., with leprosy, a history of criminal activity, or extreme poverty. Thus, genuine bride-theft was rare, and the outcome was less often successful" (pages 83-84). 
As far as the girl's family is concerned, a pregnancy resulting from the courtship or abduction would intensify the marriage negotiations and sour the two families' and clans' affinal relationships for a long time. When a pregnancy occurs along any paths to marriage where either the girl's family or boy's family refuses to initiate the marriage negotiation for some bitter reasons or grievances, the sentiment of the community would direct or cause the village's mayor as a judicial go-between to expedite the matter and get it resolved for both families.

If a voluntary elopement or bride abduction leads to marriage, it would be accepted by the two families and community at large as a proper marriage after the formal negotiations and wedding are agreed upon and completed. This recognition of the couple's marriage would bar any remaining bitterness or disputes. Also, the affinal ties of mutual cooperation between the two respective families and clans would be established. Finally, the couple's married life would proceed as if it were conceived in the normative path.

\section{Patri-Local Residence}

No matter which of the paths the couple decides to get married through, the couple would set up a living arrangement in the residence of the groom's extended family once the marriage ceremony is completed. For some reasons, if it is not possible, the couple has the option to live temporarily in one of the groom's male relatives' homes, until the house of his extended family could be expanded to accommodate their living arrangement. If the groom is a first-born son, he would generally remain with his parents' extended family to eventually take his father's position of authority over the extended family when the father is passed away. The younger married sons would also 
remain in the extended parental family's homes. Each married son occupies a separate sleeping compartment in the home, until their extended family has grown too large or crowded. By this time, the oldest son, his wife and children are the first nuclear family within that large extended family of several generations such as their grandparents, parents, children and grandchildren to leave and establish a new household of his own nearby. This process of leaving the parental extended household would follow by the birth orders of those married sons: first-born married son and his nuclear family go first, the second-born married son and his nuclear family (his wife and children) follow in second, and then follow by third or fourth-born married son and his nuclear family to the last-born married son and nuclear family.

\section{The Last-Born Son, His Nuclear Family and Traditional Duties}

The Hmong society requires that the last-born married son and his nuclear family remain permanently with their extended family to become the primary care taker of their old-aged parents and grandparents until their death. Although the older married sons and their nuclear families have moved out to establish their own residences nearby, it is very important for them to remain as close as possible to one another as one large extended family with several households. They all have a strong interdependent need for ongoing economic production and support (both material and spiritual) from each other. In addition, they have a shared rights and responsibilities to support each other for life.

\section{The Bride As A New Family Member}

The Hmong practice of patri-lineal and patri-local residence allows the bride (s) to be accepted as a new member of her husband's extended family and clan. In this way, the married couple's children would be considered as full blood members of the father's 
extended family, patri-lineal and clan for life. In some respects, the bride almost becomes "a new replaced sister and daughter" to the members of her husband's extended family. This means that she would be treated more equitably and viewed as a more important new member as soon as she gives birth to her first son, takes more household responsibilities, increases her overall production or contribution (both physical and material), and gains more influential roles and social status in the home of her husband's extended family. In other words, the bride could become a productive, valuable and important member of her husband's extended family and clan through some of the areas mentioned above.

\section{The Wife Induction To The Husband Extended Family}

The induction of the wife into the husband's extended family and clan not only enhances and strengthens the married couple's relationship, but also the ongoing affinal relationships between the couple's two extended families and clans. In fact, the Hmong kinship term for the groom's biological father and his father-in-law is the same (txiv). This means that the groom must call both his father and father-in-law "father" (txiv). This kinship term has the same application for the bride also. She must also call her biological father and father-in-law "father" (txiv). In some cases, the groom who establishes a good relationship with his parents-in-law and affinal kin has an alternative option to move his nuclear family (his wife and children) into his parents-in-law's home and share their material resources such as lands for farming, either with or without the approval of his parents and extended family. 


\section{The Traditional Hmong Family System}

\section{The Hmong Nuclear Family Within The Dominant Extended Family System}

In the Hmong society, the extended family is the dominant family form. The Hmong nuclear family only exists as a smaller component of the larger extended family system. Even the boundaries and rules governing the nuclear family are vague in the Hmong society. Therefore, a married man and his nuclear family are not completely independent from the parental extended family when he establishes his own new social and economic unit of production. The independence of his nuclear family is still limited only to the cash crop and livestock. Their means of economic production is still dependent and secured through joint efforts with other extended family members. In a small way, they produce most of what they consume. However, the materials for this production come mainly from collective property and labor. Therefore, the nuclear family, in many ways, may not survive as a completely independent social and economic unit in the traditional Hmong society. Similarly, the nuclear family is only partly independent in the spiritual world also. Many of the most important spiritual, lifesupporting ceremonies could only be conducted jointly by all the members of the entire extended family. Many of these ceremonies are conducted by the grandfather, father, first-born married son or a clan leader. As a result, all of these existing factors make the nuclear family seem less significant in the larger extended family and Hmong society which emphasizes the importance of kinship, social and economic groups over the individuals. 


\section{The Hmong Family Division of Labor: Farming and Household}

To achieve the universally essential functions of sexual, reproductive, educational, economic and affectional, and others, the division of labor within the traditional Hmong extended family and society is established as follows:

\section{Farming}

In the agricultural fields, men perform the heavy work of felling trees, cutting brush, planting, weeding, building granaries, cutting stalks and physically transporting harvested grains home from the farm. Many times they would use horses or cattle to assist the transportation of harvested crops home, if they have any domestic animals. On the other hands, women and older children help to clear the cut brush, perform lighter work in planting and weeding, flail the cut stalks, harvest crops, gather harvested grain into the baskets, and carry the smaller baskets of harvested grain home. During the harvest seasons which require heavy labor, the older family members such as grandparents would provide day care for the younger children and prepare meals at home.

\section{Household}

In the domestic area, men construct and repair houses, weapons, agricultural and household tools, musical instruments, bridles and saddles. Food preparation (cooking) and the gathering of firewood (which is shared by both genders) are the responsibilities of women and older girls. The general household chores, maintenance and clothing construction are also the work of women. More importantly, women and older girls are the primary care takers of infants, young children and elderly. Many times men and older boys give them some assistance. All the major political, social and economic transactions outside of the family belong exclusively to men. 


\section{The Hmong Form of Polygamy}

While the traditional Hmong society recognizes polygamy as another form of marriage, monogamy is, in fact, the most predominant and preferred type of marriage. The main reason is that the Hmong in general highly value a free choice of selecting prospective partners as the key predictor for successful and happy marriage. Another reason is that the bride price is so high and costly that only a few wealthy Hmong men could afford an additional wife to be their second or third spouse.

\section{The Hmong Practice of Levirate}

The Hmong type of polygamy is mostly a result of the traditional practice of levirate. Levirate is the compulsory marriage of a widow by her deceased husband's younger brother. This practice is mainly to provide for her children a new father and keep the children in the father's extended family, clan and patrilineal. Many times the widow's marriage to her younger brother-in-law is performed without her total consent. Although she has the right to voice her concerns and refuse the offer, there is a higher chance that she would not be successful. All the consanguine relatives in her deceased husband's clan would do everything they could to make her comply with the marriage. They would convince her that she should comply with the marriage for the best interests of her children. They almost pressure and force her into the marriage with her deceased husband's brother. Many times she feels like she has no alternative choices, but to go along with the pressure and recommendation from her deceased husband's extended family and clan for the sake and best interests of her children. This practice of levirate is the most common factor which has contributed to the existence of the Hmong polygamy. Most polygamous families consists of two wives. Only a few families exceed three. 


\section{The Value of Male Children Over the Female Children}

Male children are generally preferred over females due to the Hmong patrilineal descent system and the labor requirements of their agricultural society. However, both male and female children are equally loved and cared for by their parents. Males are a necessity for the continuation of their patrilineals, and the increase of their extended family and clan memberships. In the Hmong structural term, male children's value are offset somewhat by the cost of providing them with wives through the bride-price. For example, a Hmong man who has all daughters might be poor in heirs, but he would be rich in bride-price silver and goods when the daughters marry. An ideal Hmong family prefers to have an equal number of sons and daughters (for example: 3 sons and 3 daughters) to balance out each other on the traditional Hmong scale of human value (Scott, 1986). 


\section{Chapter III}

Methodology

\section{Introduction}

To begin this chapter, the writer identifies the question used in the structured interview, and describes the two chosen Hmong families who came from two different generations. It also contains the summaries of the data collection procedure and the material used to collect the data.

Research Questions Regarding General Demographic Information

1. What is your gender?: $\mathrm{M}$ $\mathrm{F}$

2. What is your age?:

3. What is your marital status?:

4. What is your occupation (optional)?:

5. What is your highest level of education?:

6. How many children do you have?:

7. Where were you born?

8. How long has your family lived in the U.S.?:

9. What is your generation in the U.S.?

Research Questions Regarding Hmong Kinship System

1. Does your family still believe in the Hmong traditional kinship system? If yes, to what extent does your family practice it?

2. Which parts of the traditional Hmong kinship system does your family still keep or practice?

3. Which parts of the Hmong kinship system does your family no longer believe or practice? If any?

4. As parents do you believe in teaching your children the Hmong kinship system as the basic education of the Hmong custom or culture? 
5. As parents do you encourage your children to use the appropriate Hmong kinship terms to address your blood and marital relatives? Explain?

Research Questions Regarding Traditional Hmong Marriage

1. Which one of the traditional Hmong marriage paths did you and your wife choose to get married? At what ages did you and your wife decide to get married?

2. Which one (s) of the traditional Hmong marriage options does your family most prefer and would like to see it (them) passed on to the next generations?

3. Which one (s) of the traditional Hmong marriage options does your family disagree with the most and would like the Hmong community to eliminate it (them) completely or partially?

4. Does your family still believe and practice the traditional Hmong bride-price, dowry and the high costs of the wedding ceremony? Explain?

5. Does your family still believe and practice the Hmong patri-local residence after your sons' marriages?

6. Does your family still believe and practice the Hmong forms of polygamy and levirate?

Research Questions Regarding Traditional Hmong Family System

1. What type of family system does your family have now? Extended or nuclear?

2. Does your family still believe and practice the traditional Hmong extended family system?

3. In your family, does each member of your family still have and perform the same traditional Hmong household roles and duties as before in Laos? 


\section{Subjects}

To protect the privacy and identity of the two selected Hmong families, the writer chose two Hmong surnames, Cha and Yang, to replace their actual last names. The surname, Cha, was given to the traditional Hmong family. Yang was given to the contemporary, nuclear Hmong family.

The subjects were two Hmong families living in the Minneapolis-St. Paul metropolitan area whose heads of the households are between the ages of twenty-seven (27) and forty-five (45). The first one was a traditional Hmong family with three (3) different generations living in the same household. It consisted of the paternal grandparents, the parents and their eight (8) children. The heads of the household were the children's parents, Mr. \& Mrs. Cha. They were in their mid-forties. The paternal grandparents were about sixty-years-old. The eight children were between the ages of 12 and 23 .

The second household was the nuclear family of Mr. \& Mrs. Yang. Their family consisted of Mr. \& Mrs. Yang and their two (2) young children, ages 3 and 6. Mr. \& Mrs. Yang were the heads of their nuclear household. They were in their late twenties and from the contemporary generation. In addition, the construction of their nuclear household reflected the new trend of the Hmong-American nuclear family system in the United States today.

\section{Selection Process}

The two Hmong families were intentionally chosen for three main reasons. The first reason was because each of the two Hmong households represented its family system. For example, the Cha family with three different generations represented the 
traditional Hmong extended family system, and the composition of the Yang family with two generations (two parents and their two children) represented the new trend of today's Hmong-American nuclear family system. The second reason was because the heads of the two households were from two different generations. Mr. \& Mrs. Cha were from the traditional generation, and Mr. \& Mrs. Yang were from the contemporary HmongAmerican generation. Finally, the third reason was that both Hmong families have been in the United States for more than 18 years.

\section{Material}

A consent for participation form written in English was given to each of the two Hmong families by the researcher. It listed the goals, risks and benefits of the study. It also explained the participants' rights to withdraw or to decline participation, and who to contact for more information. More importantly, the writer went over both the consent form and research questionnaire with all the participants in Hmong in order for them to gain a better understanding of the purpose of the study (Appendix C).

The researcher developed the questionnaire to obtain specific information about the subjects' beliefs and practices of their traditional Hmong kinship, marriage and family systems in the United States. It also intended to collect data relating to what has changed and still remained the same in their beliefs and practices of their traditional kinship, marriage and family systems as they acculturate into the American mainstream culture and society. The researcher planned to use the information from these two interviews to help identify the trends of change in the beliefs and practices of the traditional Hmong kinship, marriage and family systems in the future. 


\section{Procedure}

The participants who participated in this study were Mr. \& Mrs. Cha, Mr. Cha's elderly parents, their 8 children, Mr. \& Mrs. Yang and their two young children. They voluntarily agreed to participate in this study by signing the consent forms provided by the researcher. The researcher had direct contacts with all the participants. He spent about two hours interviewing each family separately. The two interviews took place orally in the privacy of their homes. He explained to them that their participation was voluntary, and that they could quit anytime before or during the interview process. Copies of the interview questionnaire were distributed to all participants. They were informed that their privacy and identity would be protected and kept confidential. They were also told and aware that their identifying information such as real names, addresses or other personal identities will not be used or appear in the research paper. They understood that the researcher will use two Hmong surnames as aliases to replace their actual surnames. They agreed and consented to the use of aliases to replace their actual surnames. 


\section{Chapter IV}

\section{Data Findings and Summary}

\section{Introduction}

The purpose of this study was to describe the traditional Hmong kinship, marriage and family systems based upon the writer's experiences, a thorough review of the existing literature written about the Hmong culture in these three (3) categories, and structural interviews of the two Hmong families in the Minneapolis-St. Paul metropolitan area. The two interviews were designed to gain new perspectives of both as to what has changed and what has remained the same in their beliefs and practices of the traditional Hmong kinship, marriage and family systems after living in the United States for more than eighteen (18) years. As the Hmong-American families, in general, continue to acculturate more and more into the American mainstream society and culture, the information gained from the interviews would be used to suggest the trends of change in the beliefs and practices of the traditional Hmong kinship, marriage and family systems in the near future. The findings from the two interviews were written in the format of narrative.

This chapter will answer the specific questions by discussing the data findings and summaries concerning the beliefs and practices of the two Hmong families' kinship system . The results from the two structured interviews with the two Hmong families indicated that both Hmong families still held a high regard for their traditional culture especially the three vital parts of kinship, marriage and family. These three parts were important to the infrastructure of the overall Hmong culture. In fact, they were the three essential foundations which fortified the totality of Hmong culture. Mr. Cha said, "One 
cannot begin to talk about the Hmong culture without making references to the Hmong kinship, marriage and family systems....because these three important instutitions are the basic foundations which make the Hmong culture unique, strong and completed. Without these three essential customary systems, the Hmong culture won't be where it is today,....considering the fact that Hmong people are the minority everywhere they have lived or been to."

\section{Beliefs \& Practices of The Hmong Kinship System}

Despite the length of time and the different levels of acculturation into the American mainstream society and culture, the parents of both Hmong families, including Mr. Cha's elderly parents, still maintained a strong belief regarding the traditional Hmong kinship system as a vital part of their culture. In fact, they held on to their beliefs much stronger than before because, in America, preserving their kinship system and passing it on to the next generations of their children and grandchildren had become an even more important task for them than before. Losing this vital part of their heritage while trying to acculturate with the new culture of America was not acceptable or an option for them. In their views, maintaining a balance of the two cultures — old and new—was the key to gain and unlock the best things from both cultures for them, their families and children. For this important reason, they felt it was their parental responsibilities to make sure that it happened.

To achieve this important goal, the parents and grandparents of both Hmong families put every effort they could afford to make sure that learning and practicing of their traditional kinship system was an important part of their children's ongoing education at home. They taught and encouraged their children from the early age to not 
only learn the Hmong kinship terminology, roles, mutual responsibilities and codes of conducts, but also to know how to apply them in their daily lives with each other, other extended family members and members of the Hmong community.

Although the two children of Mr. \& Mrs. Yang were still young, they had already begun to teach their oldest child, the six-year-old, the Hmong kinship terminology in Hmong such as mother, father, brother, sister, grandparent, aunt, uncle and cousin. This started when she was one-year-old. At the age of six, she had already learned fluently her Hmong kinship vocabularies, and known how to call her parents, younger brother, grandparents, cousins, aunts and uncles. As a result, her knowledge of the Hmong kinship system started to improve with her Hmong fluency and basic understanding of the Hmong kinship vocabularies.

The statements of the eight children of Mr. \& Mrs. Cha confirmed what their parents and grandparents believed and practiced. They went through a similar basic childhood education at home with their parents and grandparents. Even today, they still had occasional conversations with their parents and grandparents in order to refresh and enhance their understanding of the whole Hmong kinship system. Their parents and grandparents had taught them pretty much everything there was to know about the Hmong kinship system. In terms of practice, however, the Cha family, especially the children did not have many opportunities to apply their kinship knowledge outside of their home because not all their extended relatives lived in close proximity or in the same community or same village as in Laos. Consequently, the children usually practiced their kinship knowledge at home with their immediate family members. Some occasions outside of the home gave the children the opportunities for them to practice their kinship 
knowledge in person at the extended family gatherings, community meetings and cultural events.

The lack of opportunity to use their kinship knowledge outside of the home on a consistent basis was a drawback to their practices of the Hmong kinship system. It did create an in-consistency in their practices of the Hmong kinship system as well as their knowledge of their heritage. For self-respect and the reputation of their family, inconsistency could lead them to be forgetful sometimes, and forgetfulness could lead them to occasional embarrassments. For example, when they forgot to call their extended relatives or greet their extended family members such as aunt Mai or uncle Nhia with the appropriate kinship terms, their extended relatives either gave them a few reminders to address them appropriately or ignored them with the feeling that they lacked the proper Hmong manners and cultural awareness. When this happened in the presence of their parents or grandparents, it was even more embarrassing because they received negative responses and expressions from both their parents or grandparents and the extended relatives. This mishap could make the children feel uncomfortable, annoyed or both, depending upon their moods at that moment. Nevertheless, such reminders served as a valuable lesson for them to finally recognize the importance of knowing the Hmong kinship system and its application in their daily lives and interaction with their extended family members and members of the Hmong community. In fact, they even learned to appreciate it even more when they gained a complete understanding of it and its benefits. The two Hmong families of Cha and Yang intended to keep the whole Hmong kinship system as a vital part of the Hmong culture as long as they could and pass it on to the next generations. 


\section{Beliefs and Practices of the Traditional Hmong Marriage}

The formal Hmong marriage of Mr. \& Mrs. Cha took place in Laos. Mr. Cha was 19, and Mrs. Cha was 17-year-old when they decided to get married. They knew that in the Hmong society, there were three marriage paths available for them to choose, if they wanted to get married. These three marriage paths were (1) the formal marriage request or begging by the groom's family, (2) the voluntary elopement, and (3) the bride abduction or kidnapping. They lived in the same village, and had known each other for many years before their private courtship began. In fact, it was their brief courtship which led them to make their final decisions that they would be happy together as a married couple. They chose the voluntary elopement path to get married because it was the best option and brought the most benefits such as joy, peace and happiness to both of their families and themselves as a newly wedded couple. They did not choose the bride abduction as a marriage path because it was not civilized and respectful way to get married. They did not like the formal marriage request either because it required a large amount of money upfront before the formal marriage request could begin. In addition, Mr. Cha's family was poor, and lacked the money to help initiate the process of formal marriage request with Mrs. Cha's family at that time.

Their formal wedding took place in the home of Mrs. Cha's parents, and all aspects of their Hmong wedding went according to the Hmong marriage custom. Mr. Cha's parents paid six Hmong silver bars as the bride price to Mrs. Cha's parents. At that time, each silver bar was equivalent to $\$ 100$ U.S. dollars. In terms of U.S. dollars, the total bride price would be about $\$ 600.00$. At the end of the wedding, Mrs. Cha's parents, in return, gave one silver bar as a dowry to the newly wedded couple to start their new 
life together. In addition to the one silver bar dowry, they received large amounts of financial and material gifts such as clothing, blankets, pillows, cooking utensils and farming tools from both of their parents, their immediate families, extended relatives, friends and guests. These gifts were the resources which they used to build their new married life together.

After the wedding, the newly wedded couple returned to begin their new life in the patri-local residence of Mr. Cha's parents. They lived with his parents in the past. Today it was their turn to provide the residence and care for his elderly parents as a way of keeping the Hmong tradition of caring for the elderly during the old age. Although they would like to see their children practice and pass it on to the next generations, they did not expect their children to care for them when they are old, knowing that in America, there are options available for them. More importantly, they did not want to be a burden for their children with this tradition of caring for the elderly or the cultural obligation of caring for them when they get old. For his elderly parents, it was the decision of their family to have his elderly parents live with them and their eight children in the same household as an extended large Hmong family.

Mr. \& Mrs. Yang came to the United States with their parents as teenagers. They had the opportunity to complete high school and college here. They met each other in college, and decided to get married right after they completed their education. They were in their early twenties when they got married. Like Mr. and Mrs. Cha, they picked the voluntary elopement as their marriage option, and went through the formal Hmong marriage ceremony. Bride price and dowry were exchanged between the two families of Mr. Yang and Mrs. Yang. 
After the wedding, they returned to the residence of Mr. Yang's parents. They lived with his parents and siblings for six months before moving out of his parents' home to establish a new nuclear family of their own with their two children. As a grown son and daughter-in-law, they consulted with his parents and gained their approval before moving out to settle on their own.

The two Hmong families still held a strong belief and practice of their Hmong marriage system. In fact, the heads of both households, including Mr. Cha's parents went through the traditional Hmong marriage custom in order to be officially recognized as married couples by the Hmong community at large. As a result, their knowledge and experiences of the Hmong marriage system convinced them that it was the most suitable form of marriage available for them and the Hmong community. Although it was deeply rooted in their beliefs and practices, the Hmong kinship system was not a perfect marriage custom either.

There were four controversial things or practices in the Hmong marriage system which both families, including the eight children of Mr. \& Mrs. Cha, disagreed with and no longer practiced. These four practices were: (1) the bride price, (2) the alternative marriage path of bride abduction, (3) the Hmong form of polygamy, and (4) the practice of levirate (a compulsory marriage of a widow by her deceased husband's younger brother).

Their rationales behind the elimination and disagreements with these four practices were that:

(1) They are out of date, no longer applicable, enforceable and legal in America. 
(2) They do not make the Hmong and Hmong community look good and civilized in the eyes of the non-Hmong communities and other groups of people.

(3) The bride price carries an automatic negative assumption or stereotype that the Hmong people sell their daughters for money.

(4) The practice of bride abduction makes the Hmong look as if though they were uncivilized and savage people. It is also illegal to practice.

(5) The two practices of levirate and polygamy are legally prohibited, and do not bring success and happiness to those involved individuals and their families. In addition, these two practices bring nothing, but problems, headaches, stresses, depression and jealousy to those involved individuals and their families.

These were their reasons the two Hmong families decided to eliminate these four practices completely. They wished that the entire Hmong community would do the same.

On their parts, the parents of both families already had plans of action for their daughters in the future. When their daughters married, they would not ask the grooms or his families to pay the bride price, even if the families of the grooms insisted that they accept the bride price. However, they would still practice the dowry by converting it into a financial gift to their daughters and sons-in-law along with their other wedding presents. What they planned to do in the future with their daughters and sons-in-law was nothing new. This idea had already been implemented by some Hmong families in the United States. They were able to eliminate these unnecessary practices completely and still had successful traditional weddings with their daughters and sons-in-law. 


\section{The Traditional Hmong Family System}

The structure of the Cha family still resembled a traditional Hmong extended family with several generations living under the same roof. The Cha extended family consisted of three different generations which included Mr. Cha's elderly parents, Mr. \& Mrs. Cha, and their eight children. After living in the United States for nearly two decades, Mr. \& Mrs. Cha and his elderly parents still managed to keep their large Hmong family system attached without breaking it up into many small nuclear families. Their wish was to keep it going as long as they could, despite the multiple challenges facing them. However, by knowing the wishes of their children, they knew it would be difficult to maintain such a large extended family in America. The wishes of their children were to move out of their parents' home and establish their own nuclear families when they are ready.

The roles and responsibilities in the Cha family were still similar to those in Laos, except the fact that the Mr. \& Mrs. Cha worked full time outside of the home. Mrs. Cha and her teenage daughters still did most of the household chores and duties such as cooking, cleaning, laundering, accepting guests, caring for the young and shopping for grocery. Mr. Cha and his teenage sons, on the other hand, handled the household repairs such as plumbing, painting, fixing minor things around the house, furniture moving, automobile and household appliance repairs, lawn mowing, raking the leaves and other outside related work. The important task of passing the knowledge of their Hmong culture and disciplining the children was divided among Mr. \& Mrs. Cha and the paternal grandparents.

As the heads of the household, both the parents and grandparents had the same rights and responsibilities to discipline the children and to punish them when they 
misbehaved. The Cha family's structure of power and duties, like the power structure of a traditional Hmong family, was based upon the ages and genders of the family members in this format: male over female, and older over younger. In theory, the power structure of the traditional Hmong family stated that males have more power and responsibilities than females, and the older have more power and duties than the younger. In the power structure pyramid of the Cha extended family, Mr. Cha's father would be on the top layer due to his male gender and old age, followed by Mr. Cha's mother, Mr. Cha, his wife, their oldest child, their middle children, and their youngest child on the bottom of the pyramid.

In theory, it looked like Mr. Cha's parents would have more power and responsibilities than he or his wife and the rest of the family members. However, in practice, Mr. Cha and his wife possessed more power than his parents because, in America, they held more important responsibilities both inside and outside of the home, gained more education in terms of English fluency and knowledge, and earned incomes to support the whole family. Nevertheless, the paternal grandparents had certain power and duties. Mr. Cha's parents still had important roles to play and made countless contributions to the family with their time, effort, love, wisdom, experiences and skills.

The grandparents' greatest contribution to the success and stability of the Cha family was their countless time and effort to provide discipline, education of the Hmong culture, day care, and supervision for their grandchildren. With the grandparents staying home all day to provide day care for their children, Mr. and Mrs. Cha could go to work full time outside of the home and bring in the necessary incomes to support their large extended family. 
The Yang household was a nuclear family. It consisted of Mr. \& Mrs. Yang and their two young children. The ages of their children were three and six. The oldest child went to school all day. The youngest child was put in day care during the day, so both parents could go to work full time. They lived with their large extended families before, so they understood the advantages and disadvantages of the two types of family systems. In terms of personal preference, the nuclear family system was the better one for them and their family. Despite its lack of direct physical contact and support from the extended family members, their nuclear family system offered their family more privacy, independence, freedom, peace of mind and choices to arrange their household and set their own lifestyle according to their desires.

Unlike the traditional Hmong family system, Mr. \& Mrs. Yang handled equal shares of the household chores as well as the care, nurture and discipline of their children. They also had an equal amount of power and responsibilities both inside and outside of the home. Even their incomes from work were equally divided and spent or saved. All aspects of their nuclear family and marriage generally reflected their beliefs and acceptance of the best from both cultures. They referred to themselves as "the new Hmong-Americans of the contemporary Hmong-American generation,"....and called their current family system "the new Hmong-American nuclear family which openly accepts the best from both cultures of their new country and their native homeland." A concrete example of their acceptance of the best from both cultures was their bilingual skills (Hmong and English) or their fluent expression of ideas in both Hmong and English. They preferred to keep their nuclear family system, and had no plan to return to the Hmong extended family model. 


\section{Summary}

\section{Prediction of The Trends of Change In The Beliefs and Practices of Traditional Hmong Kinship, Marriage and Family Systems In The United States In The Near Future}

\section{Prediction}

The data collected from the interviews with the two Hmong families from two different generations in the Minneapolis-St. Paul metropolitan area indicate that the majority of the Hmong kinship and marriage systems would likely remain the same with a few changes or modifications in the near future. However, the traditional Hmong family system would be diminishing with the replacement of the nuclear family system in the near future. The followings were the findings and suggestions of change:

(1) All the essential parts of the Hmong kinship system would likely be unchanged because the results from the interviews with both Hmong families indicated that they still maintained a firm belief and practice of the Hmong kinship system. But a closer look at their practices of the Hmong kinship system showed that there was an inconsistency in their practices due to the lack of opportunity. If this indication is also accurate for the majority of the Hmong families in America today, then the overall practices of the Hmong kinship system in the Hmong community would likely be more inconsistent or even decreased in the future.

(2) The data also showed that the beliefs and practices of the Hmong marriage system in the two Hmong families still remained strong. As a result, it seemed that the essential parts of the Hmong marriage system would likely be unchanged in the near future, except the four unnecessary practices of bride price, bride 
abduction, levirate and polygamy. These four practices had already been dropped or eliminated completey by some families in the Hmong community. Therefore, it was fair to predict that they would be eliminated completely in the near future by the entire Hmong community.

(3) Finally, the data suggested that the beliefs and practices of the traditional Hmong family system seemed to be weak and on the verge of decline because the contemporary generation had no desire or interest in keeping it, except the households of the current traditional generation. It was fair to say that the future generations may want nothing to do with the Hmong extended family system. As a result, both the current shift of the contemporary generation and the possible trend of change of the next generations toward the nuclear family system would certainly put the traditional Hmong family system closer to the brink of extinction in the future.

\section{Conclusion}

Among the three traditional Hmong systems of kinship, marriage and family, the system which changed the least in the two Hmong families was the kinship custom. The marriage system had four unnecessary parts which had been eliminated or dropped from the beliefs and practices of the two Hmong families. There were some strong indications from the contemporary Hmong generation and surely the next generations that the traditional Hmong family system would not last long because the contemporary generation was shifting toward the establishment of the nuclear family system, and had no interest in maintaining the extended family households. There was a strong possibility that the future generation would follow the leads of the contemporary generation in the 
establishment of the Hmong-American nuclear family system as well. If these trends of change continue into the next generations, then the traditional Hmong family system would be moving closer to the brink of extinction. Lastly, the Hmong current predication in the United States could be best summed up with the British author John Dryden's saying, "Be not the first by whom the new is bred, nor the last to lay the old aside”(Dryden, 1972). 


\section{CITED REFERENCES}

Dryden, John. 1972. The Book of John Dryden's Essays.

Boston, MA: M.S.G. Haskell House Publisher, Inc.

Moua, Teng (1999) as a reference from the author's personal knowledge and life

experiences of the Hmong culture in the three areas of kinship, marriage and family.

Quincy, Keith. 1988. Hmong: History of A People.

Cheney, Washington: Eastern Washington University Press.

Scott, George. 1986. The Migrants Without Mountains:

The Sociocultural Adjustment Among the Lao Hmong Refugees In San Diego. Ann

Arbor, MI: A Bell And Howell Company 


\section{Appendix A}

The Hmong 18 Clans' Names

The 18 clans are named and identified by their family surnames. These clan names have been passed down from generation to generation unbrokenly. To this day, Hmong still use the same clan names which are also their surnames. The spellings of these 18 clans' names are as follows:

\section{English Spelling}

1. Cha or Chang

2. Cheng

3. Chue

4. $\quad$ Fang

5. Hang

6. Her

7. Kha or Khang

8. $\quad$ Kong

9. Kue

10. Lee or Ly

11. Lo, Lor or Lao

12. Moua

13. Pha

14. Thao

15. Vang

16. Vu or Vue

17. Xiong

18. Yang

\section{Hmong Spelling}

1. Tsab

2. Tsheej

3. Tswb

4. Faj

5. Ham

6. Hawj

7. Khab

8. Koo

9. Kwm

10. Lis

11. Lauj

12. Muas

13. Phab

14. Thoj

15. Vaj

16. Vwj

17. Хyooj

18. Yaj 


\section{Appendix B}

\section{Hmong Patrilineal Descent System With Six Generations Chart}

By using a Hmong male ego as the starting point in the children's generation.

Great Grandparent

Grandparent

Parent

Children

Grandchildren

Great Grandchildren

1. The great grandparent's generation includes ego's consanguine great grandparents, his great grandfather's brothers, his great grandfather's brothers' wives, his great grandfather's male parallel cousins and their wives.

2. The grandparent's generation includes ego's consanguine grandparents, his grandfather's brothers, his grandfather's brothers' wives, his grandfather's male parallel cousins and their wives.

3. The parent's generation includes ego's consanguine parents, his father's brothers, his father's brothers' wives, his fathers' male parallel cousins and their wives.

4. The children's generation includes ego, his siblings, parallel cousins (both male and female) his male parallel cousins and their wives.

5. The grandchildren's generation includes ego's children, and his brothers' children, male parallel cousins' children.

6. The great grandchildren's generation includes ego's grandchildren, his brothers' grandchildren, and his male parallel cousins' grandchildren. 


\section{Appendix C}

\section{Project Title: The Hmong Culture: Kinship, Marriage \& Family Systems.}

I, a graduate student at the University of Wisconsin-Stout in the Marriage and Family Therapy Program, am conducting a research project titled, the Hmong Culture: Kinship, Marriage and Family Systems. I would appreciate your participation in this study.

It is not anticipated that this study will present any medical risk or social risk to you. The information gathered will be kept strictly confidential and any reports of the findings of this research will not contain your name or any other identifying information.

Your participation in this project is completely voluntary. If at any time you wish to stop participating in this research, you may do so, without coercion or prejudice. Just inform the researcher.

Once the study is completed, the analyzed findings would be available for your information. In the meantime, if you have any questions, please contact Teng Moua, the researcher, at the University of Wisconsin-Stout Marriage and Family Therapy Program, Menomonie, WI 54751, phone number (715) 232-2404

Questions or concerns about participation in the research or subsequent complaints should be addressed first to the researcher or research advisor and second to Sue Foxwell, Human Protections Administrator, UW-Stout Institutional Review Board for the Protection of Human Subjects in Research, 11 Harvey Hall, UW-Stout, Menomonie, WI 54751, phone number (715) 232-2477.

\section{Consent Form}

I understand that my participation in this study is strictly voluntary and I may discontinue my participation at any time without prejudice. I understand that my participation in this study is to investigate the subject, Hmong Culture: Kinship, Marriage and Family Systems. I further understand that any information about me that is collected during this study will be held in the strictest of confidence and will not be part of my permanent record. I understand that in order for this research to be effective and valuable certain personal identifiers need to be collected. I also understand that the strictest of confidentiality will be maintained throughout this study and that only the researcher(s) will have access to the confidential information. I understand that at the conclusion of this study all records which identify individual participation will be destroyed.

Signature of Participant: Date:

Signature of Parent/Guardian (If under 18 years of age)

Date: 
